\title{
Introduction: Menstruation as Embodied
}

\author{
Tomi-Ann Roberts
}

This section begins where the subfield itself began-at the site of the human body. Of course we experience menstruation in the body, which is always already embedded in particular interactional and sociocultural discourses. The chapters in this section reflect on the power of institutions to subjugate and discipline bodies to probe the many ways the menstrual cycle becomes a site of sexualization, self-objectification, and abjection, of shame and shaming, of medicalization, disability and dysfunction, and even a source of moral panic. Thus the embodied experience of menstruation, from menarche to menopause, is rarely cause for celebration or even contentment, and is instead typically a project to manage properly as an essential component of "doing (feminine) gender." The most important of these, argues Jill Wood here, is concealment, and the menstrual hygiene industry steps into provide the tools necessary for this self-disciplining body project.

Research on perceptions of menstruating women reveal the widespread belief that the reproductive body has the power to cause disgust-like reactions in others, to alter women's personalities, making them "crazy," and that menstrual blood itself is a stigmatizing "mark" (see Johnston-Robledo and Chrisler). As well, the premenstrual phase of the cycle is widely associated with emotional lability, impulsivity, and irrationality. Sally King writes of how the "myth of the irrational female" has led to a prioritizing of psychological symptoms in diagnosis, treatment, and research on PMS, despite the fact that these are neither the most commonly experienced nor most disruptive of menstrual-related changes experienced by women.

Indeed Jane Ussher and Janette Perz describe how many women take up the position of the monstrous feminine (emotionally out of control, animal-like, and fat) in their own descriptions of their premenstrual embodiment. And yet, these self-conceptions need not only position the body as abject; they can also be a form of agentic subjectivity. Ussher and Perz find 
clues in women's PMS narratives that allow them to acknowledge the complexities in adopting the subject position "PMS sufferer," which both evokes connotations of the monstrous feminine and makes meaning of women's physical and emotional distress, through legitimizing their experiences as real and requiring support.

Centuries-old beliefs such as the wandering womb that causes hysteria and distress continue to be reflected in popular discourse, leading to real consequences not only for how we understand healthy menstruation, but also for identifying and treating menstruation-related disorders. Heather Guidone discusses how endometriosis affects an estimated 176 million people worldwide, causing pain and reduced quality of life, and yet this condition continues to be dismissed by both patients and practitioners alike. When symptoms are poorly understood, lengthy delays in diagnosis result, and the negative impact of endometriosis is exacerbated further.

Three chapters here discuss what all this mystification means for girls' embodiment as they mature into menstruating beings. Bobier, Piran, and Stubbs and Sterling each reveal the ways strongly enforced discourses of femininity, as well as girls' own self-objectification and self-sexualization "corset" (as Piran puts it) the way they can inhabit their bodies. Girls link menarche and sexuality and yet lack language to make this connection a source of embodied self-understanding, power, or enjoyment. Bobier's teen interviewees spoke of wishing to be "good girls" (that is, asexual), however, their fears of rape and pregnancy revealed their awareness that they are not fully in control of the way their developing bodies are seen or treated. Piran argues that the possibilities for positive embodiment at menarche hinge on girls' relational connections and Stubbs and Sterling offer concrete suggestions for menstrual education as an opportunity to provide girls with more accurate and positive views of their genitals and sexual selves.

The transnational engagement that concludes this section amplifies the voices of those whose menstruating bodies exist in fraught conditions. We hear from a formerly incarcerated woman, a woman with disabilities, and a woman who lives and works in disaster-prone regions. In each of these cases popular simple solutions to menstrual management ("let's give everyone free tampons and pads!") will not fly, either because they are unusable by some bodies or under certain conditions, but even more so because these interventions leave stigma-which these women face not only as menstruators but also as marginal — unaddressed. Their stories are a powerful reminder of the need for equitable and inclusive menstrual policies, diverse product designs, and above all, a framing of the menstruating body not as a site of humiliation and degradation, but rather of care.

Of course in matters of embodiment related to menstruation in a misogynist culture, one is damned if she does and damned if she doesn't. So even menopause is typically constructed not as a normal, healthy developmental transition, but instead as an illness. As I experience menopause myself, and fumble my way through such challenging body betrayals as heart palpitations 
and dizziness, wanting answers and not finding any, I take tremendous heart in Dillaway's closing words in her chapter: "Thinking about ourselves as living in this uncertain time, rather than just getting through it, may be the first step to understanding and owning the impact of menopause and reproductive aging."

The menstrual body is a complex reality that refuses simplification. It is obfuscated and degraded by misogynist assumptions that worm their way into our very own embodied experiences of our reproductive bodies. But I find hope in each of these chapters, all of which are saying, one way or another, that we deserve to take care of our menstruating and menopausal bodies, that we have a right to unburden ourselves from the project of concealing, medicating, or enduring pain or debasement of our bodies, and instead to take them up ourselves, whoever and wherever we are, gently, as our own.

Open Access This chapter is licensed under the terms of the Creative Commons Attribution 4.0 International License (http://creativecommons.org/licenses/ by $/ 4.0 /$ ), which permits use, sharing, adaptation, distribution and reproduction in any medium or format, as long as you give appropriate credit to the original author(s) and the source, provide a link to the Creative Commons license and indicate if changes were made.

The images or other third party material in this chapter are included in the chapter's Creative Commons license, unless indicated otherwise in a credit line to the material. If material is not included in the chapter's Creative Commons license and your intended use is not permitted by statutory regulation or exceeds the permitted use, you will need to obtain permission directly from the copyright holder.

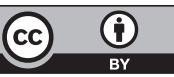

